\title{
Characteristics of fleshy fruits in southeast Alaska: phylogenetic comparison with fruits from Illinois
}

\author{
Anna Traveset, Mary F. Willson and Miguel Verdú
}

\begin{abstract}
Traveset, A., Willson, M. F. and Verdú, M. 2004. Characteristics of fleshy fruits in southeast Alaska: phylogenetic comparisons with fruits from Illinois. - Ecography 27 : $41-48$.
\end{abstract}

\begin{abstract}
Over 30 species of fleshy-fruited plants are found in southeast Alaska. In this paper we examine traits such as plant growth form, phenology, fruit color, seed load, pulp dry weight, and pulp nutrient content and compare them with those of fruits from central Illinois. Two comparative methods (continuous time Markov model and phylo-Anova) were used to compare both qualitative and quantitative traits between the two regions. Although fleshy-fruited plants from SE Alaska appear to be predominantly shrubs or herbs in contrast to central Illinois, where trees and vines tend to be more common, no significant differences among growth forms were found when accounting for plant phylogeny. In SE Alaska, most fruits mature in August and September, whereas most fruits mature later in the autumn in Illinois. Red fruits are more common in Alaska than in Illinois, where blue-black fruits predominate. Alaskan fruits have a significantly greater seed load than fruits in Illinois, while pulp dry weight does not differ between the two regions. Although the proportion of sugars and lipids in the pulp was not statistically different between the two regions, total reward of the pulp (estimated as the absolute amount of sugars plus twice the amount of lipids, as lipids provide about twice the energy of sugars) was greater in Alaskan than in Illinois fruits. Neither phylogenetic constraints nor selection by frugivores appear to account fully for the regional distribution of fruit characteristics.
\end{abstract}

A.Traveset (atraveset@uib.es), Mediterranean Inst.of Advanced Studies (CSIC-UIB), Cl Miquel Marqués 21, E-07190 Esporles, Spain. - M. F. Wilson, 5230 Terrace Place, Juneau, AK 99801, USA. - M. Verdú, Centro de Investigaciones sobre Desertificación (CSIC-UV), Cami de La Marjal s/n, Apdo. Oficial, E-46470 Albal, Valencia, Spain.

Despite the numerous studies on the ecology and evolution of plant-frugivore interactions (see recent reviews in Jordano 2000, Herrera and Pellmyr 2002, Levey et al. 2002) we still know little about the relative importance of frugivores in determining geographical variability in fruit traits. At a local scale, some authors argue that frugivore behavior does not contribute much to explaining the diversity of fleshy-fruits (Herrera and Pellmyr 2002 and references therein), while others suggest it does (e.g. Izhaki 2002). At a broader scale, there seems to be little evidence that frugivores act as important selective agents, as many fruit traits appear to be phylogenetically conservative (e.g. Fischer and Chap- man 1993, Jordano 1995, Eriksson and Ehrlén 1998). On the other hand, some studies do suggest that current selection pressures, possibly including those exerted by frugivores, may be important (e.g. Nakanishi 1996, Kollmann 2000, Hampe 2003).

It is clearly essential to consider phylogenetic relatedness in any study that examines potential sources of selection in the evolution of fruit traits. So far, only a few studies have compared structural or chemical fruit characteristics at a large geographical scale (e.g. Mack 1993, Kollmann 2000, Hampe 2003), controlling for phylogeny by comparing higher taxonomic levels (e.g. families) among regions (Mack 1993) or by analyzing

Accepted 2 July 2003

Copyright (C) ECOGRAPHY 2004

ISSN 0906-7590 
intraspecific variation along a latitudinal gradient (Hampe 2003).

The goal of our study is to compare quantitative and qualitative traits of fleshy fruit from two regions of North America by taking into account the phylogenetic relatedness among taxa and thus avoiding the pseudoreplication derived from common ancestry (Harvey and Pagel 1991). We compared new data on fleshy-fruit characteristics in southeast Alaska with previously published information from Illinois, in central North America (Willson and Thompson 1982, Johnson et al. 1985), the only other region of the continent with a comparable data set.

The temperate rainforest of SE Alaska is notable for the high diversity (for its latitude, ca $55-60^{\circ} \mathrm{N}$ ) and abundance of fleshy fruits that are dispersed by frugivorous vertebrates. Over 30 fleshy-fruited species are known to occur there, and some are among the most common plants in the understory. These fruits are consumed by bears and other "carnivores" (Willson 1993), as well as many species of birds, including corvids, thrushes, some warblers, and waxwings (e.g., Willson and Comet 1993, Willson 1994, Traveset and Willson 1997, 1998). The post-glacial historical array of frugivores in SE Alaska and Illinois is rather similar, except that SE Alaska has fewer medium-sized mammals such as foxes (Willson 1991, Wilson and Ruff 1999). If frugivores have exerted major selection pressures on fruit characteristics in recent history, then the similar frugivore communities in the two regions should produce similar arrays of fruit traits, despite the differences in plant community composition.

\section{Study area and methods}

Most fruits were collected near Juneau, Alaska (ca $58.4^{\circ} \mathrm{N}, 134.3^{\circ} \mathrm{W}$ ), in $1989-1992$ (and 1996 for salmonberry, Rubus spectabilis), but a few samples came from elsewhere in northwestern North America (Table 1). This area is north-temperate coastal rainforest, with an overstory chiefly of Sitka spruce Picea sitchensis and western hemlock Tsuga heterophylla, and scattered successional stands of black cottonwood Populus trichocarpa, willow (Salix spp.), and alder Alnus sitchensis. Muskegs (with Sphagnum moss and lodgepole (shore) pine, Pinus serotina), sedge meadows, alpine tundra, and beach meadows are the common open habitats. Annual rainfall often exceeds $2500 \mathrm{~mm}$. Most of the species in this study typically occur in forest or forest fringes, but several occur mostly in open habitats that have a scattered distribution: Vaccinium caespitosum, V. uliginosum, $V$. vitis-idaea, Empetrum nigrum, Oxycoccus microcarpon, Rubus arcticus, R. chamaemorus, Fragaria chiloensis. Some fleshy-fruited plants are far more common in the interior than in coastal SE Alaska, including Amelanchier, Juniperus, Shepherdia, Geocaulon and Arctostaphylos uva-ursi.

Analysis of fruit pulp ( $\%$ moisture, lipid, and nonstructural carbohydrates or sugars) was conducted by the Agricultural Research Station of the Univ. of Alaska, in Palmer, AK, from wet fruit-pulp (seedless) samples sent from Juneau. Relative levels of total reward per fruit in Alaska were estimated as the absolute amount of sugars plus twice the amount of lipids, as lipids provide about twice the energy of sugars (Winick et al. 1988, Bairlein 1996). Although it matters which fats and sugars are involved (Levey and Martínez del Río 2001, McWilliams et al. 2002), this difference between lipids and sugars is a reasonable approximation.

Data from SE Alaskan fleshy fruits were compared to those gathered in central Illinois (latitude: $40.1^{\circ} \mathrm{N}$ $88.2^{\circ} \mathrm{W}$ ) (Willson and Thompson 1982, Johnson et al. 1985). Mean annual precipitation in this area is ca 1000 $\mathrm{mm}$.

The plant phylogeny used to run the phylogenetic comparisons between the fruit traits of Alaska and Illinois was that published in Soltis et al. (2000) with a grafted clade (Rosaceae) resolving phylogeny at the genus level. We thus constructed a super-tree and assumed equal branch lengths (Ackerly 2000, Verdú 2002). Because phylogeny was unknown for several groups (e.g. Rubus, Ribes, Ericaceae), our phylogenetic tree contained several "soft" polytomies (Garland and Díaz-Uriarte 1999).

Discrete characters (growth form, fruit ripening season and color), were compared between the two regions by means of the DISCRETE software available at < http://www.ams.rdg.ac.uk/zoology/pagel/ >, which allows testing for correlated evolution of binary characters on phylogenetic trees by means of a continuous time Markov model (Pagel 1994). This is achieved by comparing the fit (likelihood) of a model in which the two traits are allowed to evolve independently against other model in which traits evolve in a dependent fashion. As far as we know, no software exists to test for correlated evolution in multi-state characters, and thus, we decided to pool multi-state characters into binary ones. Growth form was classified as "herbs" vs "woody" (trees, shrubs and vines) and ripening season was classified as "early" (summer) vs "late" (autumn/ winter). The nine fruit colors were pooled as much as possible, resulting into three categories similar to those proposed by Hampe (2003): 1) black-blue, 2) red-orange, 3) infrequent colors (brown, green, gold, white, yellow). Following the DISCRETE manual for characters with more than two characters, we represented fruit color as a series of binary traits, each contrasting a group labeled " 1 " with all of the others. Thus, we run three tests for testing fruit colors differences in the two study sites (black-blue vs the rest of colors; red-orange vs the rest of colors; infrequent colors vs the rest of colors). Poly- 
Table 1. Characteristics of fleshy fruits in southeast Alaska. W = overwintered fruits collected the following year. All samples collected in southeast Alaska, except as indicated $(\mathrm{OR}=$ Oregon, $\mathrm{BC}=$ northern $\mathrm{BC}$, or interior Alaska). Species with multiple entries are represented by multiple samples from different locations or times. [Taxonomic notes: Vaccinium alaskense and $V$. ovalifolium merged by Vander Kloet, Oplopanax $=$ Echinopanax, Sambucus racemosa $=S$. callicarpa, Malus fusca $=$ M. diversifolia, Maianthemum canadense $=M$. dilatatum.] Fruit samples were composites of several individual plants (no exact numbers are available).

\begin{tabular}{|c|c|c|c|c|}
\hline & Fruit color & Seeds/fruit (mean, N) & $\%$ lipid & $\%$ sugars \\
\hline \multicolumn{5}{|l|}{ Araliaceae } \\
\hline Oplopanax horridum & Red & $2.0(20)$ & 2.4 & 30.3 \\
\hline \multicolumn{5}{|l|}{ Caprifoliaceae } \\
\hline Sambucus racemosa & Red & $2.2(20)$ & $33.6,25.2$ & $8.3 ; 5.6$ \\
\hline & Orange & $3.3(20)$ & $26.7,32.8$ & $6.1 ; 6.0$ \\
\hline Symphoricarpus albus & White & $1.6(20), 2.1(20)(\mathrm{OR})$ & 1.5 & 24.7 \\
\hline Viburnum edule & Red & $1.0(20)$ & $5.6 \mathrm{~W}, 7.4,7.2$ & $18.1 \mathrm{~W}, 29.8,26.1$ \\
\hline \multicolumn{5}{|l|}{ Cornaceae } \\
\hline Cornus canadensis & Red & $1.0(20)$ & 4.1 & 30.6 \\
\hline C. stolonifera & White & $1.0(40)$ & 25.4 & 14.9 \\
\hline \multicolumn{5}{|l|}{ Eleagnaceae } \\
\hline Shepherdia canadensis & Red-orange & $1.0(100)$ & $2.6,0.7$ & $14.8 ; 31.2$ \\
\hline \multicolumn{5}{|l|}{ Empetraceae } \\
\hline Empetrum nigrum & Black & $9.1(20)$ & -12.0 & $3.7 \mathrm{~W}, 25.8$ \\
\hline \multicolumn{5}{|l|}{ Ericaceae } \\
\hline Arctostaphylos uva-ursi & Red & (several) & $4.3,4.3 \mathrm{~W}$ & $28.1,28.0 \mathrm{~W}$ \\
\hline Oxycoccus microcarpon & Red & $9.6(20)$ & $\begin{array}{l}6.4 \mathrm{~W} \\
8.8,10.4\end{array}$ & $\begin{array}{l}16.3 \mathrm{~W} \\
21.3,25.4\end{array}$ \\
\hline Vaccinium alaskense & $\begin{array}{l}\text { Blue-black } \\
\text { (bloom) }\end{array}$ & $27.3(20)$ & 5.0 & $30.5,47.3$ \\
\hline V. caespitosum & Blue (bloom) & $21.3(20)$ & 3.6 & 38.3 \\
\hline V. ovalifolium & Blue (bloom) & $67.4(15)$ & 3.1 & 31.0 \\
\hline V. parvifolium & Red & $17.6(20)$ & 7.9 & 33.1 \\
\hline V. uliginosum & $\begin{array}{l}\text { Blue-black } \\
\text { (bloom) }\end{array}$ & $16.1(20)$ & 6.0 & 32.1 \\
\hline V. vitis-idaea & Red & $12.8(20)$ & $\begin{array}{l}3.1 \mathrm{~W} \\
3.4,3.5\end{array}$ & $\begin{array}{l}26.5,23.1 \mathrm{~W} \\
21.2,20.4\end{array}$ \\
\hline \multicolumn{5}{|l|}{ Ranunculaceae } \\
\hline Actaea rubra & Red & $11.7(24), 9.2(25)$ & $1.7,2.6,1.8$ & 15.5 (Sept),,- 5.9 \\
\hline \multicolumn{5}{|l|}{ Rosaceae } \\
\hline Amelanchier alnifolia & Blue (bloom) & $2.8(20)$ & 0.6 & 29.8 \\
\hline Fragaria chiloensis & Red & $29.6(10)$ & - & - \\
\hline Malus fusca & Yellow/red & $1.8(20), 5.9(25)$ & $3.6,5.4,5.2,3.5$ (mature) & 9.6, 9.5, 14.6, 19.0 (mature) \\
\hline Rosa nutkana & Red & $12.5(20), 10.3(20)$ & $0.9,1.3,0.8$ & $21.7,21.9,26.4$ (Nov) \\
\hline Rubus arcticus & Red & $16.9(10)$ & - & 20.2 \\
\hline R. chamaemorus & Yellow/orange & $8.3(10)$ & 3.6 & 27.7 \\
\hline R. parviflorus & Red & $115.9(10)$ & - & - \\
\hline R. pedatus & Red & 1 (20), $2-3$ drupes/flower & $4.7,2.1$ & $24.3,36.5$ \\
\hline \multirow[t]{3}{*}{ R. spectabilis } & Red & $45.1(11), 45.5(20)$ & $\begin{array}{l}0.4,1.3,1.6,2.2,-0.5,3.6 \\
10(\mathrm{OR})\end{array}$ & $\begin{array}{l}29.0,35.0,37.8,37.3,38.4,40.4,33.2 \\
30.4 \text { (OR) }\end{array}$ \\
\hline & Orange & $35.0(10), 41.9(22)$ & 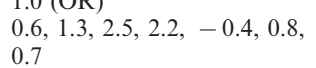 & $\begin{array}{l}37.4,33.7,41.1,35.6,43.2,40.4,34.2 \text {, } \\
33.7\end{array}$ \\
\hline & & & $1.3(\mathrm{OR})$ & $27.0(\mathrm{OR})$ \\
\hline Sorbus sitchensis & Red-orange & $4.1(20)$ & $3.8,6.1$ & $10.3,12.7$ \\
\hline \multicolumn{5}{|l|}{ Santalaceae } \\
\hline Geocaulon lividum & Orange & $1.0(10)$ & $1.4,0.7$ & 20.0 (July), 57.0 (Sept) \\
\hline \multicolumn{5}{|l|}{ Saxifragaceae } \\
\hline Ribes bracteosum & $\begin{array}{l}\text { Blue-black } \\
\text { (bloom) }\end{array}$ & $12.0(18)$ & 5.7 & 26.9 \\
\hline R. lacustre & Black & $10.9(19)$ & 2.5 & 21.9 \\
\hline R. laxiflorum & $\begin{array}{l}\text { Blue-black } \\
\text { (bloom) }\end{array}$ & $22.0(11)$ & 6.5 & 28.1 \\
\hline \multicolumn{5}{|l|}{ Liliaceae } \\
\hline $\begin{array}{l}\text { Maianthemum } \\
\text { canadense }\end{array}$ & Red & $1.8(19), 1.8(19)$ & $1.4,-$ & $34.1,28.7 \mathrm{~W}$ \\
\hline Clintonia borealis & Blue & $8.3(16)$ & - & - \\
\hline Streptopus amplexifolius & Red & $22.1(18)$ & $3.6,4.5$ & $38.6,22.9$ \\
\hline S. roseus & Red & $8.9(20)$ & 4.2 & 29.5 \\
\hline \multirow[t]{2}{*}{ S. streptopoides } & Red & $11.3(8), 9.6(20)$ &,- 1.5 (Sept) & 36.2, 26.7 (Sept) \\
\hline & Orange & $9.4(19)$ & - & 40.2 (Sept) \\
\hline \multicolumn{5}{|l|}{ Cupressaceae } \\
\hline Juniperus communis & Blue (bloom) & $2.9(21)$ & $6.2,6.1 \mathrm{~W}$, interior $\mathrm{AK}$ & $27.4,27.4 \mathrm{~W}$ \\
\hline
\end{tabular}


tomies are not allowed in the DISCRETE software, and therefore, we arbitrarily resolved them to bifurcations of infinitesimal length (see Nosil 2002 for this procedure and its consistency with other procedures).

To compare the quantitative variables, i.e. seed load, pulp dry weight, and proportion of sugars and lipids, we ran phylogenetical Anova (phylo-Anova hereafter) in the PDAP software (Garland et al. 1993). The phylo-Anova creates, by computer simulation, a null distribution that incorporates the phylogenetic relationships between species. Data was transformed either logarithmically (in the case of seed load and pulp dry weight) or with the angular transformation (in the case of proportion of sugars and lipids) to achieve normality. Branch length standardization was verified for each compared variable by correlating the absolute values of each contrast versus its standard deviation (Garland et al. 1992).

The null hypothesis in all the statistical tests was that the plant traits are similar between Alaska and Illinois once phylogeny was accounted for. Thus, statistically significant loglikelihood ratios (LR) and F-values mean that the study trait differs between both geographical regions after controlling for phylogenetic relatedness.

The files containing both the phylogeny and the tip values for the continuous (pdi files for PDAP software) and the discrete (ppy files for DISCRETE software) traits are available upon request to authors. A total of 36 species from 23 genera from 12 families from SE Alaska was compared with 22 species from 21 genera from 17 families from central Illinois. Only four families (Rosaceae, Caprifoliaceae, Cornaceae, and Ranunculaceae) were shared between the two regions.

\section{Results}

Although vertebrate-dispersed woody species appeared to be relatively less frequent in Alaska than in Illinois (Willson 1991), the frequency distribution of growth forms (herbs vs woody plants) did not differ significantly between the two regions after accounting for the phylogeny of the species $(\mathrm{LR}=1.11 ; \mathrm{p}=0.71)$. Mature fleshy fruits are most diverse and abundant in Alaska in summer in contrast to Illinois, where most plants $(>77 \%)$ bear ripe fruits later in the autumn/winter $(\mathrm{LR}=8.93 ; \mathrm{p}=0.002)$. Exceptions in SE Alaska are Rubus spectabilis (which usually presents ripe fruit in July and early August) near sea level, and Maianthemum canadense (which seldom ripens until late autumn, when almost all potential dispersal agents have disappeared for the season; these fruits are then commonly available in spring after snowmelt). At higher elevations, fruits of $R$. spectabilis and Vaccinium spp. ripen later and may be available into October, and fruits of some species (including Viburnum edule, Oplopanax horridum, and Empetrum nigrum) regularly overwinter.
Red-orange is the most common color category (64\%) for ripe fruits in Alaska, followed by blue-black (31\%); the opposite is observed in Illinois, where blue-black fruits represent $45 \%$ of all colors present in our dataset and red fruits represent $32 \%$. Infrequent colors are collectively rare in SE Alaska $(5 \%)$ but not in Illinois $(23 \%)$ (Table 1). The higher frequency of red-orange fruits on Alaska is marginally significant when common ancestry is taken into account $(\mathrm{LR}=3.742 ; \mathrm{p}=0.084)$, while the frequencies of black-blue $(\mathrm{LR}=0.764 ; \mathrm{p}=$ $0.835)$ and infrequent color fruits $(\mathrm{LR}=2.53$; $\mathrm{p}=$ 0.183 ) do not differ between sites. There are no Alaskan species with bicolored fruiting displays, but polymorphism in fruit color is well developed in Rubus spectabilis (Traveset and Willson 1998, Gervais et al. 1999) and is known regionally also in Sambucus racemosa (red or orange), Streptopus streptopoides (red or orange), Actaea rubra (red or white) and Vaccinium ovalifolium (blue or white).

Seed load per fruit was higher in SE Alaska than in Illinois. The phylo-Anova showed significant differences between the two regions $\left(\mathrm{F}_{1,57}=9.36, \mathrm{p}=0.02\right)$. The mean number of seeds per fruit was 14.71 in Alaska (range $1-116, \mathrm{n}=36 \mathrm{spp}$ ) and 4.93 in Illinois (range 1$6, \mathrm{n}=22 \mathrm{spp}$.). Single-seeded fruits are uncommon in SE Alaska (ca $6 \%$ of fleshy-fruited species) compared to Illinois $(32 \%)$. Pulp dry weight did not differ significantly between SE Alaskan and Illinois fruits $\left(\mathrm{F}_{1,49}=\right.$ $3.95, \mathrm{p}=0.17$ ), the means being $0.067 \mathrm{~g}$ (range: $0.01-$ $0.36 \mathrm{~g}$ ) and $0.035 \mathrm{~g}$ (range: $0.001-0.127 \mathrm{~g}$ ), respectively.

The proportions of sugars and lipids in the pulp of fruits from SE Alaska were also similar to those found from the Illinois sample when controlling for phylogeny $\left(F_{1,50}=1.27, p=0.43\right.$ for sugars, and $F_{1,50}=3.20$, $\mathrm{p}=0.21$ for lipids); the mean proportion of sugars was 27\% (range: $7-39 \%$ ) and $17 \%$ (range: $3-53 \%$ ) for Alaska and Illinois, respectively, whereas that of lipids was $6 \%$ (range: $1-30 \%$ ) and $8 \%$ (range: $0.4-40 \%$ ), respectively. Because the absolute amount of sugar or lipid per fruit depends also on the dry mass of fruit pulp, consideration of the total reward per fruit provides a very different picture of potential food reward per fruit consumed (Table 2). Thus, taking into account that lipids provide about twice as much energy as sugars, we found that fruits in Alaska had a significantly greater reward than those in Illinois $\left(\mathrm{F}_{1,46}=8.64, \mathrm{p}=0.04\right)$, means being $22.36 \mathrm{mg}$ (range: $3.8-91.08 \mathrm{mg}$ ) and $11.26 \mathrm{mg}$ (range: 0.73-29.74 mg), respectively. Converted to caloric content, those averages are equivalent to 0.38 and 0.19 kJoules, respectively (sugars provide 17.2 kJoules/g; Bairlein 1996). The species with the highest relative energy reward in Alaska appear to be Rosa nutkana, Malus fusca, Rubus chamaemorus, and R. spectabilis (Table 2).

Sugar and lipid content of fruits sometimes differed among samples of the same species (Table 1). Lower 
Table 2. Estimated amount of lipid, sugar, and total reward per fruit. Dry mass values rounded to nearest hundredth of a gram for purposes of estimation. Total reward estimated by 2(lipid) + sugar. Fruit samples were composites of several individual plants (no exact numbers are available).

\begin{tabular}{|c|c|c|c|c|}
\hline Species & Dry mass (g) & Lipid (mg) & Sugars (mg) & Total \\
\hline Oplopanax horridum & 0.03 & 0.6 & 9.0 & 10.2 \\
\hline Sambucus racemosa & 0.01 & 2.9 & 0.7 & 6.5 \\
\hline Viburnum edule & 0.04 & 2.8 & 10.0 & 15.6 \\
\hline Cornus canadensis & 0.01 & 0.4 & 3.0 & 3.8 \\
\hline C. stolonifera & 0.03 & 7.5 & 4.5 & 19.5 \\
\hline Empetrum nigrum & 0.02 & 2.4 & 5.2 & 10.0 \\
\hline Arctostaphylos uva-ursi (W) & 0.08 & 3.2 & 22.4 & 28.5 \\
\hline Oxycoccus microcarpon & 0.02 & 1.6 & 4.6 & 7.8 \\
\hline Vaccinium alaskense & 0.06 & 3.0 & 23.4 & 29.4 \\
\hline V. caespitosum & 0.04 & 1.6 & 15.2 & 18.4 \\
\hline V. ovalifolium & 0.08 & 2.4 & 24.8 & 29.6 \\
\hline V. parvifolium & 0.03 & 2.4 & 9.9 & 14.7 \\
\hline V. uliginosum & 0.04 & 2.4 & 12.8 & 17.6 \\
\hline V. vitis-idaea & 0.04 & 2.4 & 8.4 & 10.8 \\
\hline Actaea rubra & 0.02 & 0.4 & 1.8 & 2.6 \\
\hline Malus fusca & 0.17 & 6.8 & 32.3 & 45.9 \\
\hline Rosa nutkana & 0.36 & 3.6 & 86.4 & 93.6 \\
\hline Rubus arcticus & 0.13 & - & 26.0 & - \\
\hline R. chamaemorus & 0.16 & 6.4 & 44.8 & 57.6 \\
\hline R. pedatus & 0.02 & 0.6 & 6.2 & 7.4 \\
\hline R. spectabilis & 0.23 & 2.3 & 82.8 & 87.4 \\
\hline Sorbus sitchensis & 0.08 & 4.0 & 8.8 & 16.8 \\
\hline Geocaulon lividum & 0.06 & 0.6 & 30.0 & 31.2 \\
\hline Ribes bracteosum & 0.06 & 3.6 & 16.2 & 23.4 \\
\hline R. lacustre & 0.03 & 0.9 & 6.6 & 8.4 \\
\hline R. laxiflorum & 0.03 & 2.1 & 8.4 & 12.6 \\
\hline Maianthemum canadense & 0.02 & 0.2 & 6.8 & 7.2 \\
\hline Streptopus amplexifolius & 0.03 & 1.2 & 9.3 & 11.7 \\
\hline$S$. roseus & 0.02 & 0.8 & 6.0 & 7.6 \\
\hline S. streptopoides & 0.02 & 0.2 & 6.8 & 7.2 \\
\hline
\end{tabular}

amounts of sugars were recorded for summer samples of Geocaulon, Streptopus streptopoides, Vaccinium vitisidaea, and Actaea, compared to samples from later in the season, suggesting a possible seasonal change in nutrients that was not reflected in fruit appearance. In contrast, sugar content was lower in winter samples of Empetrum and Viburnum, indicating that the overwintered fruits of this species may not offer much food value; this result for $V$. edule contrasts with that found for $V$. opulus (Jones and Wheelwright 1987, Witmer 2001). Variation among samples for some other species was not clearly related to season of collection and may reflect either differences among locations (as found for other species of Vaccinium, Vander Kloet and AustinSmith 1986) or perhaps unknown differences in pulp processing in the laboratory.

\section{Discussion}

Attempts to explain observed variation in fruit characteristics usually involve taxonomic, phylogenetic patterns or current environmental conditions and selective pressures. Phylogenetic constraints have a strong influence on fleshy fruit traits, reducing the likelihood of finding close relationships between fruit traits and features of the current biotic and abiotic environments (e.g. Herrera 1986, 1987, 1995, Jordano 1995). For instance, SE Alaska has large mammals that could eat large fruits, but no large fruits are present and no fruit species is characterized by distinctive traits typical of mammal-dispersed fruits outside North America (reviewed by Willson 1991).

Our comparative study showed geographic differences, within North America, in four of the fleshy-fruit traits examined, namely phenology, seed load, frequency of fruit colors, and nutrient reward of the pulp. These differences emerge when the phylogenetic constraints derived from common ancestry are controlled. It is tempting, therefore, to suggest that fleshy-fruit traits in a geographical area may result from local selection pressures (Thompson 1994), recent and/or current. Evolutionary changes can be rapid (Ashley et al. 2003), so responses to a selection mosaic need not require long time periods. Local differences are not surprising and have been detected along a latitudinal gradient even within a species (Hampe 2003). However, what little is known about local selection pressures does not fully explain all the observed differences.

The earlier fruit maturation found in SE Alaska compared to Illinois may reflect regional differences in frugivore activity patterns; bird migration is earlier, but much less abundant, in coastal Alaska, and bears prepare for and enter hibernation earlier in Alaska 
than in the midwest. This would seem to support the "adaptive delay hypothesis" (which predicts a negative correlation between latitude and date of earliest ripening; Guitián 1998). However, latitudinal differences in fruit maturation times would also be predicted from abiotic climatic factors. In a literature review from western Europe, Fuentes (1992) found only a small fraction of fleshy-fruited bird-dispersed species behaving as predicted by such adaptive delay hypothesis. Flowering time, competition among plants for disperser-attraction, dispersal by non-migrating birds or stationary mammals, and phylogenetic inertia are, among others, possible explanations for such phenological deviations (Eriksson and Ehrlén 1998).

Geographic differences in seed load may be due to an array of factors, both biotic and abiotic. Selection for a higher number of seeds per fruit in SE Alaska might occur if, for example, fruit removal rates were so low that there is an advantage to putting more seeds in each fruit. We have observed that, in many years in SE Alaska, numerous fruits just drop from the maternal plants without being consumed by vertebrates. Alternatively, greater seed loads might be possible for fruits in coastal rainforest if seed loads were limited by water.

Widespread variation is found in fruit-color, even within a genus (e.g. Alaskan Vaccinium and Ribes have either blue-black or red fruits; pers. obs., Viereck and Little 1972). Fruit color preferences by frugivores appear to be both variable among individuals and flexible (Willson et al. 1990, Willson and Comet 1993, Murray et al. 1993, Willson 1994, Traveset and Willson 1998) and not closely related to the frequency distribution of fruit colors in a region (Gervais et al. 1999). In any case, frugivore foraging is only one of several factors that might drive the evolution of fruit colors, and many different factors influence fruit choices (Willson and Whelan 1990). Furthermore, the widespread occurrence of fruit color polymorphism (Willson 1986, this study) shows that considerable genetic variation exists within species.

Variation among congeners is also found in total nutrient reward per fruit (two species of Cornus, Table 1; Arctostaphylos uva-ursi, see Table 1, vs A. rubra in northern British Columbia, 1.9\% lipid, 38.6\% sugars; Rosa nutkana, see Table 1, vs $R$. acicularis in northern British Columbia, 0.8\% lipid, 16-17\% sugars). Similar variation is seen also within genera in Europe (Herrera 1986) and in central Illinois (Viburnum, Cornus, unpubl.). Variation within genera, and especially within species, suggests that traits that vary at these taxonomic levels are less controlled by phylogeny than traits that are invariant at these levels. In such cases, there may be a relatively greater role of recent or current selection pressures, but identifying the sources of selection remains difficult.
Fruits from SE Alaska had a greater nutrient reward than those from Illinois, but it is not reasonable to argue merely that there is stronger selection by frugivores for more rewarding fruits in SE Alaska. The most rewarding fruits (Sorbus, Malus) in SE Alaska are too big for many frugivorous birds to handle easily and, thus, most birds are unlikely to be selective factors for this fruit trait in these species. Most of the richest fruits in SE Alaska are uncommon: Malus is scattered along beach fringes, Sorbus on the edges of muskegs and beaches, Rubus chamaemorus in patches in muskeg, Cornus stolonifera in some riparian zones, and Rosa is seldom seen. The relative rarity and patchy distribution reduces the likelihood of consistent selective foraging by frugivores, so selection pressures exerted by frugivores would be difficult to detect.

The nutrient analyses performed in this study did not distinguish the types of sugars or lipids in fruit pulp (except for Rubus spectabilis; Traveset and Willson 1998), although there is now evidence that both sugars and lipids can differ greatly in their nutritional value to particular frugivores and that frugivores differ considerably in their abilities to use various sugars or lipids (e.g. Levey and Martínez del Rio 2001, McWilliams et al. 2002). More detailed analyses of sugars and lipids in northern species of fleshy fruits are desirable. Furthermore, it is important to know more about interactions of dietary fruits with other foods (e.g., Witmer 2001) as well as seasonal differences in frugivore digestion (e.g. Whelan et al. 2000).

Biogeography and the history of plant distributions probably contribute to the observed differences between Alaska and central Illinois more than the differential selection that frugivores may have exerted in the two regions. Much of the northwestern part of North America has been deglaciated for only a few thousand years, but in the absence of knowledge about periglacial distributions of fleshy-fruited plants and their vertebrate mutualists, it is oversimplified merely to invoke the relatively short post-glacial evolutionary time as an explanator of the lack of close mutual adaptation. Vertebrates no doubt played a major role in the colonization of post-glacial lands by fleshy-fruited plants (Snow and Snow 1988), but other limitations (e.g., germination requirements) have probably restricted the northward expansion of some species that are dispersed by vertebrates farther south.

Geographical patterns in fleshy fruit traits probably are based on phylogeny, current selection pressures, and historical factors controlling range expansions and contractions. But too little is yet known about the patterns themselves to permit detailed assessments of causal processes. Furthermore, the consequences of geographical differences in fleshy-fruit traits for frugivore ecology have yet to be examined. The globally widespread occurrence of the frugivore/plant mutualism 
suggests its biological importance, but much remains to be learned about its evolution and ecology.

Acknowledgements - Funding for fruit-pulp analyses was provided by the Pacific Northwest Research Station. We thank the Palmer lab of the Univ. of Alaska for analyses of fruit pulp, Ted Garland and Mark Pagel for providing the PDAP and DISCRETE software, respectively, for the phylogenetic analyses, and Carlos Herrera for helpful comments on an earlier version of the paper.

\section{References}

Ackerly, D. D. 2000. Taxon sampling, correlated evolution, and independent contrasts. - Evolution 54: 1480-1492.

Ashley, M. V. et al. 2003. Evolutionarily enlightened management. - Biol. Conserv. 111: 115-123.

Bairlein, F. 1996. Fruit-eating in birds and its nutritional consequences - Comp. Biochem. Physiol. A 113: 215-224.

Eriksson, O. and Ehrlén, J. 1998. Phenological adaptations in fleshy vertebrate-dispersed fruits of temperate plants. - Oikos 82: 617-621.

Fischer, K. E. and Chapman, C. A. 1993. Frugivores and fruit syndromes: differences in patterns at the genus and species level. - Oikos 66: 472-482.

Fuentes, M. 1992. Latitudinal and elevational variation in fruiting phenology among western European bird-dispersed plants. - Ecography 15: 177-183.

Garland, T. Jr and Díaz-Uriarte, R. 1999. Polytomies and phylogenetically independent contrasts: examination of the bounded degrees of freedom approach. - Syst Biol. 48: $547-558$.

Garland, T. Jr, Harvey, P. H. and Ives, A. R. 1992. Procedures for the analysis of comparative data using phylogenetically independent contrasts. - Syst. Biol. 41: 18-32.

Garland, T. Jr et al. 1993. Phylogenetic analysis of covariance by computer simulation. - Syst. Biol. 42: 265-292.

Gervais, J. A., Noon, B. R. and Willson, M. F. 1999. Avian selection of the color-dimorphic fruits of salmonberry, Rubus spectabilis: a field experiment. - Oikos 84: 77-86.

Guitián, P. 1998. Latitudinal variation in the fruiting phenology of a bird-dispersed plant (Crataegus monogyna) in western Europe. - Plant Ecol. 137: 139-142.

Hampe, A. 2003. Climate effects on fruit traits in vertebratedispersed temperate plants. - J. Biogeogr. 30: 1-10.

Harvey, P. H. and Pagel, M. D. 1991. The comparative method in evolutionary biology. - Oxford Univ. Press.

Herrera, C. M. 1986. Vertebrate-dispersed plants: why they don't behave the way they should. - In: Estrada, A. and Fleming, T. H. (eds), Frugivores and seed dispersal. Junk, pp. $5-18$.

Herrera, C. M. 1987. Vertebrate-dispersed plants of the Iberian Peninsula: a study of fruit characteristics. - Ecol. Monogr. 57: $305-331$.

Herrera, C. M. 1995. Plant-vertebrate seed dispersal systems in the Mediterranean: ecological, evolutinary, and historical determinants. - Annu. Rev. Ecol. Syst. 26: 705-727.

Herrera, C. M. and Pellmyr, O. 2002. Plant-animal interactions: an evolutionary approach. - Blackwell.

Izhaki, I. 2002. The role of fruit traits in determining fruit removal in east Mediterranean ecosystems. - In: Levey, D. J. et al. (eds), Seed dispersal and frugivory: ecology, evolution and conservation. CABI Publ., pp. 161-175.

Johnson, R. A. et al. 1985. Nutritional values of wild fruits and consumption by migrant frugivorous birds. - Ecology 66 : $819-827$.

Jones, E. and Wheelwright, N. T. 1987. Seasonal changes in the fruits of Viburnum opulus, a fleshy-fruited temperate-zone shrub. - Can. J. Bot. 65: 2291-2296.
Jordano, P. 1995. Angiosperm fleshy fruits and seed dispersers: a comparative analysis of adaptation and constraints in plantanimal interactions. - Am. Nat. 145: 163-191.

Jordano, P. 2000. Fruits and frugivory. - In: Fenner, M. (ed.), Seeds. The ecology of regeneration in plant communities, 2nd ed. CABI Publ., pp. 125-165.

Kollmann, J. 2000. Dispersal of fleshy-fruited species: a matter of spatial scale? - Persp. Plant Ecol. Evol. Syst. 3: 29-51.

Levey, D. J. and Martínez del Río, C. 2001. It takes guts (and more) to eat fruit: lessons from avian nutritional ecology. - Auk 118: 819-831.

Levey, D. J. et al. (eds) 2002. Seed dispersal and frugivory: ecology, evolution and conservation. - CABI Publ.

Mack, A. L. 1993. The sizes of vertebrate-dispersed fruits: a neotropical-paleotropical comparison. - Am. Nat. 142: $840-856$.

McWilliams, S. R., Kearney, S. B. and Karasov, W. H. 2002. Diet preferences of warblers for specific fatty acids in relation to nutritional requirements and digestive capabilities. - J. Avian Biol. 33: 167-174.

Murray, K. G. et al. 1993. The influence of seed packaging and fruit color on feeding preferences of American robins. - In: Fleming, T. H. and Estrada, A. (eds), Frugivory and seed dispersal: ecological and evolutionary aspects. Kluwer, pp. 217-226.

Nakanishi, H. 1996. Fruit color and fruit size of birddisseminated plants in Japan. - Vegetatio 123: 207-218.

Nosil, P. 2002. Transition rates between specialization and generalization in phytophagous insects. - Evolution 56: 1701-1706.

Pagel, M. 1994. Detecting correlated evolution on phylogenies: a general method for the comparative analysis of discrete characters. - Proc. R. Soc. Lond. B 255: 37-45.

Snow, B. and Snow, D. 1988. Birds and berries. - Poyser.

Soltis, D. E. et al. 2000. Angiosperm phylogeny inferred from 18S rDNA, rbcL, and atpB sequences. - Bot. J. Linn. Soc. 133: $381-461$.

Thompson, J. N. 1994. The coevolutionary process. - Chicago Univ. Press.

Traveset, A. and Willson, M. F. 1997. Effect of birds and bears on seed germination of fleshy-fruited plants in a temperate rainforest of southeast Alaska. - Oikos 80: 89-95.

Traveset, A. and Willson, M. F. 1998. Ecology of the fruitcolour polymorphism in Rubus spectabilis. - Evol. Ecol. 12: $331-345$.

Vander Kloet, S. P. and Austin-Smith, P. J. 1986. Energetics, patterns and timing of seed dispersal in Vaccinium Section Cyanococcus. - Am. Midl. Nat. 115: 387-396.

Verdú, M. 2002. Age at maturity and diversification in woody angiosperms. - Evolution 56: 1352-1361.

Viereck, L. A. and Little, E. L. Jr 1972. Alaska trees and shrubs. - USDA For. Serv., Agriculture Handbook 410.

Whelan, C. J. et al. 2000. Linking consumer-resource theory and digestive physiology: application to diet shifts. - Evol. Ecol. Res. 2: 911-934.

Willson, M. F. 1986. Avian frugivory and seed dispersal in eastern North America. - Curr. Ornithol. 3: 223-279.

Willson, M. F. 1991. Dispersal of seeds by frugivorous animals in temperate forests. - Rev. Chilena Hist. Nat. 64: 537-554.

Willson, M. F. 1993. Mammals as seed-dispersal mutualists in North America. - Oikos 67: 159-176.

Willson, M. F. 1994. Fruit choices by captive American robins. - Condor 96: 494-502.

Willson, M. F. and Thompson, J. N. 1982. Phenology and ecology of color in bird-dispersed fruits, or why some fruits are red when they are 'green'. - Can. J. Bot. 60: 701-713.

Willson, M. F. and Whelan, C. J. 1990. The evolution of fruit color in fleshy-fruited plants. - Am. Nat. 136: 790-809.

Willson, M. F. and Comet, T. A. 1993. Food choices by northwestern crows: experiments with captive, free-ranging and hand-raised birds. - Condor 95: 596-615. 
Willson, M. F., Graff, D. A. and Whelan, C. J. 1990. Color preferences of frugivorous birds in relation to the colors of fleshy fruits. - Condor 92: 545-555.

Wilson, D. E. and Ruff, S. (eds) 1999. The Smithsonian book of North American mammals. - Smithsonian Inst. Press, Washington DC.
Winick, M. et al. (compilers and eds) 1988. The Columbia enclyclopedia of nutrition. - Putnam, New York.

Witmer, M. C. 2001. Nutritional interactions and fruit removal: cedar waxwing consumption of Viburnum opulus fruits in spring. - Ecology 82: 3120-3130. 